nection with the grant of degrees, diplomas, and certificates to engineering students, that great importance should be attached to laboratory and experimental work performed by individual students, as well as to their progress in mathematical and scientific studies, rather than that degrees and so on should be granted on the results of terminal or final examinations. It is urged that facilities for post-graduate work by engineering students in higher technical institutions should be much increased; and it is admitted by almost all authorities that the improvements of engineering education depend greatly on the attitude of employers towards the recommendations made by the committee, and employers are urged to extend the facilities to engineering students for post-graduate study and research.

The recommendations of the committee in respect of engineering training embody the conclusions arrived at by an examination of the replies just summarised, and it is unnecessary to do more than point out the respects in which the recommendations amplify the opinions set forth in the schedule prepared for distribution. The recommendation respecting the introductory workshop course explained above recognises that at present there are practical difficulties in arranging for this workshop year being interposed between the school and college work, and that employers may consider the arrangement detrimental to their interests. The committee suggests, however, that these difficulties should not be insurmountable, and the general agreement as to its advantageous effect on training leads it to hope that practical trial may be given to the plan.

Concerning attendance at evening classes during the introductory workshop course, the committee thinks it is most important that all boys should at least maintain their scholastic acquirements, and it is considered that this result might be secured, by private tuition or otherwise, without undue physical strain. So, too, the general recommendation that the introductory workshop course should be followed immediately by attendance at college is modified. It is stated that in some cases-as, for example, when boys are intended to become mechanical engineers--it may be advantageous to complete the practical training before entering college; but, if this is done, private tuition or evening classes must be the rule during the years of practical work.

The longest of the recommendations urges the need for a sound and extensive knowledge of mathematics ia all branches of engineering. The committee endorses the practically universal opinion that a sufficient time should be allotted to the study of pure mathematics during the common college course, and that the extent to which individual students can be carried in mathematics must be decided by the teachers.

Such are, in brief, the more important of the committee's recommendations, and it is interesting to compare these with some aspects of American practice. The rule in the engineering courses of the colleges of the United States, which it must be remembered always follow a prolonged secondary education, is that in the first two years of the course-which generally lasts four years-a fair amount of time is given to mathematics, English, modern languages, and experimental science, and it is chiefly in the workshop and drawing office that the specialisation towards engineering is apparent during these years. Specialisation begins to show itself prominently during the third year, and mechanical technology and electrotechnics are more or less taken up in the mechanical and electrical engineering courses. In the fourth year a crowd of engineering subjects is frequently introduced. But as Prof. Ripper remarks in his Mosely Commission report, " From the English standpoint too much importance may be attached to prolonged literary training, and not enough importance to the practical training of students during the earlier years of their career, nor to the cultural value of a scientific and professional education." But in no respect are American conditions more different from those at home than in the attitude of the employers of labour toward higher education. As Dr. Walmsley has testified in a recent report (see NATURE, vol. 1xx., p. 23r), "Without exception the officials interviewed asserted that, far from having any difficulty in placing the graduates turned out year by year from the engineering courses, for the last few years the graduate class has had every one of its individual members engaged for remunerative work before the completion of the course at college."

Such are the importance of the report of the Institution of Civil Engineers and the care which has been expended upon its preparation, that it is to be hoped it will be read alike by all responsible for the educa. tion of our future engineers, and by those who are in a position to employ the young men when their training is complete. In face of the severe competition between nations for industrial supremacy, it becomes a national duty for each and all, who can assist and forward the means of preparing the men in whose care our manufactures and general mercantile welfare will rest, to do their best; and a debt of gratitude is due to the Institution of Civil Engineers for the work it has accomplished.

A. T. S.

BALLOONS AND KITES IN THE SERVICE OF METEOROLOGY.

DURING recent years a considerable amount of information has been accumulated about the conditions which prevail in the higher strata of the atmosphere. Although observations of temperature and humidity were made by Glaisher from a free balloon more than fifty years ago, and later Mr. Archibald used kites to determine the change of wind velocity with elevation, it is only in the last ten years that a systematic attempt has been inaugurated to obtain information. There is now a fair amount of observational material awaiting someone with the necessary skill and leisure to work it up, and it is much to be hoped that the task may be taken in hand shortly, so that the results obtained in various countries and by various organisations or individuals may be arranged and coordinated, in order that further inquiry may be pushed along the most promising lines.

The means of observation available are practically kites and small unmanned balloons carrying selfrecording instruments, aided to some extent by direct observations made from manned balloons; and the only obstacle to continuous daily or even hourly readings at moderate heights is that of expense.

The free balloons possess the advantages of reaching heights unattainable by any other means, and of being independent of weather conditions. Either paper or rubber balloons are used of about six to ten feet diameter. These balloons are filled with hydrogen, and carry up with them a self-recording meteorograph made as light as possible; they frequently reach heights exceeding ten miles, and it is seldom, at least on the more thickly inhabited parts of the Continent, such as France and Germany, that they are lost. Each balloon carries an attached label offering a small reward to the finder, and the address to which information is to be sent, and in general the meteorograph is recovered with its record in a decipherable condition within a few weeks or a month. It is desirable that the balloon should fall as near as possible to its starting point, and with a rubber balloon this

NO I906, vOL. 74] 
is effected in the following manner. The balloon is only partially filled with gas, and is then securely tied up. As it rises the external pressure is lessened and the gas inside expands, until finally the rubber is no longer able to stand the strain and the balloon bursts. A small parachute is used to prevent a too rapid fall of the metcorograph, and sometimes a second smaller balloon, filled to a less extent, so that it does not burst, is also attached; the second balloon takes the place of the parachute, but is employed that it may float over the position of the fallen meteorograph, and direct attention to it. With paper balloons an automatic arrangement is used by which the balloon is freed when it reaches a certain height. The general result is that the meteorograph returns to the earth within a time of about an hour, and within a distance of a hundred miles from the starting point.

Observations obtained by the help of kites have the advantage of being less costly, but they are dependent on the weather conditions, and it is not often that heights exceeding two miles are reached. At Lindenberg in Germany, the best equipped station for the purpose in existence, last year a height of just on four miles was reached by a train of kites. Given sufficient wind it is a perfectly simple process to send a kite up to the height of a few thousand feet, although if the wind be very strong it is not so simple to draw it back again. The chief obstacle to attaining great altitudes is the wind resistance upon the cord or wire which holds the kite, and it is on this account that the strongest and thinnest obtainable steel wire is used. The wire introduces many technical difficulties; it is difficult and to some extent dangerous to handle, and although capable of withstanding a great strain if fairly used, if a kink is once formed the piece of wire in which it is, is utterly useless. Usually steel music wire, the kind of wire used in a piano in fact, of about I-32in. in diameter is used; this will bear a weight of 25 olbs., and weighs I6lbs. to the mile. With a good kite presenting 77 square feet of surface to the wind and 8000 feet of this wire, a vertical height of one mile is easily reached under favourable conditions of wind, and one kite of this size has carried a meteorograph to 8000 feet of height. The conditions are not always favourable; instead of a steady wind of twenty-five to thirty miles per hour, increasing somewhat with altitude, which affords the besi conditions, it not infrequently happens that quite different velocities are found in different strata. It is impossible to get through a stratum in which the velocity is under fifteen miles per hour, and if a velocity of much over forty miles per hour is encountered in the lower strata, the kite is very likely to be damaged or the wire broken. At greater heights a higher velocity is not so likely to cause damage, since the air is less dense, and (a point of perhaps far greater importance) the wind is far steadier.

Hence it is easily seen that to reach very great heights with a train of kites, in addition to having apparatus of the best design and quality, exceptional weather conditions must hold, and the observer must succeed in straining his wire just short, but only just short, of its breaking point. The attempt very often ends in the breaking of the wire near the winch, and the departure of five or six miles of wire and six or eight kites.

Very interesting results have been given by the unmanned balloons. It has been found that when they have reached a great height they fall in some locality lying to the east of their starting point, not necessarily due east, but on a more easterly meridian. Since they pass far beyond the upper limit of the cirrus cloud, this fact confirms the statement that in the temperate latitudes the upper currents are always from some westerly point. M. Teisserenc de Bort also finds that balloons sent up in a cyclone tend to move away from the centre at great heights, thus showing that the cyclonic circulation is not a mere surface phenomenon. He also states that at ten miles height the air is warmer over the cyclone, and colder over the anticyclone.

When observations by means of kites were first started by Mr. Rotch, at Blue Hill, Boston, U.S., it was hoped that the long disputed point as to the origin of cyclones would be elucidated; so far this has not been the case.

Ferrel, the well-known American meteorologist, held that cyclones were convectional effects, and that they were maintained chiefly by the latent heat of condensation of the vapour in the central and rainy part. Dr. Hann on the other hand considers that cyclones are what may be described as driven eddies in the general circulation of the atmosphere. Opinion on the Continent, based on the results of observations obtained by balloons and kites, seems to be in favour of Dr. Hann's hypothesis, but Mr. Clayton, of Blue Hill, U.S., considers that the ascents there made favour the convectional theory. The results of some two hundred kite ascents which I have obtained in England and Scotland, with an average height of about one mile, seem to me to give no evidence one way or the other. I think, however, that a fundamental crror has generally been assumed in the discussion. We know that in a gas in equilibrium under a conservative system of forces the isothermal and isobaric surfaces must be identical; this point at least is not open to question. It is not, therefore, the proper test to consider whether the temperature in a cyclone is greater or less than in an anticyclone at the same height, but the test is whether it be greater or less at points on the same isobaric surfaces; and the isobaric surfaces in temperate latitudes may well differ from surfaces of equal height above mean sea level by a thousand feet or more.

W. H. Dines.

\section{THE BICENTENARY CELEBRATION OF THE} BIRTH OF BENJAMIN FRANKLIN.

C $\mathrm{HE}$ oldest scientific society in the new world is, I believe, the American Philosophical Society of Philadelphia. The Society was founded by Benjamin Franklin, son of an English father and born at Boston, Massachusetts, in January, I706. It was. natural that the bicentenary of the birth of a man of such extraordinary and diverse genius as Franklin should be commemorated in his native land, and accordingly during the past winter the Society issued invitations to leading universities and societies throughout the world to be present, through their delegates, at a festival to be held at Philadelphia from April i7 to 20. The date of the meeting was no doubt chosen because Philadelphia is liable to be intolerably hot in the summer, and would certainly be deserted at that season by many of the leading members of the Society, yet the chosen time was not a good one for European delegates, since academic duties would certainly preclude any large attendance from across the seas. Although, then, there were actually present only some half-dozen delegates from Europe, yet many European societies were represented by honorary members of American nationality, and sent addresses of congratulation to the Philosophical Society. The United States and Canada were naturally in great force, and the hundred and fifty or two hundred delegates who attended formed an imposing body of men of scientific repute.

The proceedings began on the evening of April 17, No. I 906, VOL. 74] 